\title{
EI derecho a la libertad de profesar la fe católica frente a las restricciones de movimiento y reunión a raíz del COVID-191
}

\author{
The right of freedom to profess the Catholic faith in the face of restrictions of movement \\ and assembly in the wake of COVID-19 \\ Víctor M., Vera-García ${ }^{2}$; Francisco, Duarte-Tello ${ }^{3}$
}

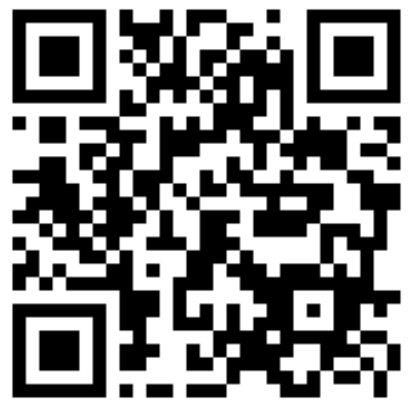

Fecha de recibido: $28-11-2020$

Fecha de aceptado: 19-02-2021

\section{(cc) BY-NC-ND}

Esta obra está bajo una licencia de Creative Commons Reconocimiento-NoComercialSinObraDerivada 4.0 Internacional

\begin{abstract}
RESUMEN
El presente artículo es fruto de una investigación que se enfocó en analizar la forma en que los creyentes católicos comenzaron a vivir y continúan viviendo su fe a raíz de la pandemia provocada por el virus SARS-CoV-2. Tiene por objetivo pues, desentrañar si las medidas de restricción de movilidad y reunión dictadas por distintos gobiernos tuvieron en cuenta las expresiones religiosas y describir cómo los feligreses y autoridades católicas se adaptaron a dichas circunstancias. La técnica de investigación del trabajo es hermenéutica y el tipo de investigación cualitativo. Los hallazgos de la investigación muestran un cambio en la forma en que los fieles profesan la fe, acentuado por la pandemia y las restricciones de esta. Se han adaptado para el culto religioso las diversas herramientas que aportan medios audiovisuales, digitales y las redes sociales.
\end{abstract}

Palabras claves: Derecho a la salud pública, derecho de libertad de culto, medidas de restricción, movilidad y reuniones, religión católica.

\begin{abstract}
This article is the result of research focused on analyzing the way in which Catholic believers began to live and continue to live their faith in the wake of the SARS-CoV-2 pandemic. It aims to unravel whether the mobility and assembly restriction measures dictated by different governments took into account religious expressions and to describe how Catholic parishioners and authorities adapted to such circumstances. The research technique of the work is hermeneutic, and the type of research is qualitative. The research findings show a change in the way worshippers profess their faith, accentuated by the pandemic and its restrictions. The various tools provided by audiovisual, digital and social media have been adapted for religious worship.
\end{abstract}

Keywords: Catholic religion, mobility and assembly, restriction measures, right to profess faith, right to public health.

Cómo referenciar este artículo:

Vera-García., V., \& Duarte-Tello., F. (2021). El derecho a la libertad de profesar la fe católica frente a las restricciones de movimiento y reunión a raíz del COVID-19. Revista Politica Globalidad y Ciudadanía, 7(14), 152-180. https://doi.org/10.29105/pgc7.14-8

\footnotetext{
${ }^{1}$ Este artículo es producto de un proyecto de investigación desarrollado por el interés particular de los autores, sin un financiamiento especifico, iniciado en 2020 y finalizado en 2021.

${ }^{2}$ Academia Interamericana de Derechos Humanos, México. Especialista en Género y Derechos Humanos por la Academia Interamericana de Derechos Humanos, de la Universidad Autónoma de Coahuila, auxiliar de investigación, Academia Interamericana de Derechos Humanos, Email: victorveragarcia90@gmail.com, Código ORCID: 0000-0002-9360-3067.

${ }^{3}$ Instituto Coahuilense de Acceso a la Información Pública, México. Especialista en Derechos Políticos por Perspectiva Internacional y Comparada, Humanos por la Academia Interamericana de Derechos Humanos, de la Universidad Autónoma de Coahuila, subdirector de indicadores y calidad, Instituto Coahuilense de Acceso a la Información Pública, Email: francisco.duarte@ icai.org.mx, Código ORCID: 0000-0003-4772-2599.
} 


\section{1.- INTRODUCCIÓN}

La problemática planteada en el presente trabajo es el cuestionamiento de si los distintos gobiernos en el mundo tomaron en consideración las prácticas religiosas dentro de los distintos decretos de restricción de movilidad y reunión. Así mismo se plantea la interrogante de cómo los feligreses y autoridades religiosas respondieron a dichas restricciones. Por tanto, el objetivo que nos fijamos en el presente trabajo tiene un carácter descriptivo, el cual consiste en mostrar las distintas regulaciones para hacer frente a la pandemia, sus consideraciones en cuanto a las actividades religiosas y por último presentar un panorama sobre cómo se adaptaron las citadas actividades por parte de la población religiosa.

Cabe señalar que el alcance de la presente investigación se limita a las situaciones observadas en relación con la religión católica, dejando si acaso como comentario las situaciones enfrentadas por otras denominaciones religiosas. Así mismo los países que se tomaron como referencia son aquellos que consideramos cuentan con una tradición católica importante, enfocándonos en países tanto latinoamericanos como europeos. La razón de que la investigación haya abarcado este tipo de países se debe en primer lugar a que buscábamos no sólo una tradición católica, sino una tradición que fuera similar en cuanto a vivencias y prácticas, cuestión que se cumple con el grupo de países estudiados debido a su relación histórica colonial con los países europeos (Ramírez Calzadilla, 2002, p. 215). Así mismo buscamos países cuyos sistemas constitucionales y jurídicos fueran de derecho continental, cuestión que también se cumple en los países de los cuales se habla en el presente artículo.

A lo largo de la investigación nos topamos con distintas limitaciones como las barreras del lenguaje en ciertos países, como fue el caso de Alemania o Italia o la falta de dominio de las particularidades de cada sistema constitucional y jurídico pese a las similitudes que guardan de forma general. Sin embargo, la limitante que más pesó en el trabajo fue la falta de publicidad y difusión de las medidas tomadas por los países en torno a la situación del ejercicio de los derechos religiosos, pues estas cuestiones sólo se hacen evidentes si se realizan las búsquedas en lugares muy específicos o si se tiene conocimiento de ellas a través de otros trabajos doctrinales.

Ahora bien, la razón para realizar la presente investigación es debido a que mucho se ha discutido sobre los distintos derechos que se han visto afectados a raíz de la pandemia provocada por el COVID19. Sin embargo, el derecho de culto es uno de los poco estudiados, siendo que en general el derecho a 
Vera-García., V., \& Duarte-Tello., F.

la libertad de religión es poco estudiado y cuando se analiza, dichos análisis se enfocan más en la libertad de creencias y no tanto en la implicación del derecho sobre la realización de actividades religiosas.

Antes de terminar con esta parte de la introducción cabe mencionar que a lo largo del texto se estarán utilizando de manera indistinta las siguientes expresiones: profesión de culto, profesión de fe, libertad religiosa y derecho de culto. Todas estas expresiones hacen referencia a un aspecto del derecho de libertad religiosa, el cual es poder participar en las actividades de culto. En el caso de la religión católica la actividad más común y recurrente es el de la celebración eucarística, mejor conocida como la misa. No obstante, se debe recordar que existen otro tipo de actividades de la fe católica como son el rezo de rosarios u otros rezos comunitarios, la realización de retiros espirituales y las celebraciones propias de fiestas específicas como la Cuaresma, la Pascua, el Adviento o la Navidad; celebraciones que tienen intrínsecamente un carácter comunitario.

Una vez señalado lo anterior procedemos a hablar de los antecedentes en la introducción para posteriormente llegar al apartado del fundamento teórico.

La libertad es uno de los mayores anhelos humanos, pues es una de las necesidades fundamentales de las personas y las sociedades que construyen. Por tanto, es uno de los primeros derechos consagrados en los ordenamientos jurídicos de los Estados nacientes y se ha mantenido como tal a lo largo de los distintos instrumentos de derechos fundamentales y humanos a lo largo del tiempo. Una de las vertientes del derecho de libertad, es el de la libertad de culto que ha adoptado distintas formas y ha sido respetado poco, nada o mucho en las distintas culturas humanas. El culto se ha dado a distintas fuerzas sobrenaturales o seres superiores que han variado conforme a espacios geográficos, la cultura de los creyentes, tradiciones y demás cualidades de cada seno social. Las religiones que nacen de las creencias y los cultos de dichas entidades son uno de los pilares fundamentales de la humanidad. Estas religiones han ayudado a justificar los desarrollos y sistemas de valores, así mismo han servido para justificar las limitaciones de la propia conducta humana. Dejar de lado a las religiones en la historia de la humanidad sería omitir un ámbito importante de nuestra evolución, debido a que las creencias religiosas han contribuido a dar forma a estructuras sociales desde la antigüedad. Si bien, muchos actos atroces de la humanidad se han generado por las mismas, no podemos negar que parte del desarrollo de nuestra conciencia se debe en gran medida a las creencias, que inclusive lograron formar un sistema jurídico que no sólo las protege, sino que establece las pautas y criterios para que, a pesar de la pluralidad cultural, exista un equilibrio dentro de la convivencia social. 
Ahora bien, la religión como cualquier derecho debe observar ciertas condiciones de respeto de otros individuos, que puedan o no tener estas mismas prácticas. El desarrollo de espacios donde se puedan ejercitar las distintas prácticas de los creyentes ha sido una de las tareas fundamentales de cada gobierno. La sana convivencia y el sentido de comunidad al momento de practicar los distintos cultos sirven a las personas como parte fundamental de su libertad por lo que reprimirlas sería frenar el libre desarrollo de la personalidad de cada uno. El actual panorama de la emergencia sanitaria generada por el COVID-19 ha creado una situación problemática, pues debido a las limitaciones impuestas por los Estados a la libre circulación y la realización de actividades de carácter social, ha evitado que miles de devotos puedan acudir a sus templos o lugares de culto a fin de llevar a cabo sus ceremonias religiosas de forma ordinaria. Esto ha provocado que las personas e instituciones religiosas se planteen nuevas alternativas para practicar la profesión de la fe.

Así pues, el propósito del presente ensayo es presentar una perspectiva general de las nuevas vivencias dentro del catolicismo generadas precisamente por la pandemia del COVID-19. En este documento se analizará primero cómo se ha vivido a lo largo de los años esta religión y después se presentará un panorama contemporáneo anterior a la situación del coronavirus. Posteriormente se hablará de la relación que existe entre el derecho de libertad de culto y las restricciones para salvaguardar otros derechos fundamentales como la salud pública. A continuación de eso se presentará un breve panorama comparado de las restricciones en algunos países europeos y latinoamericanos, y la relación de dichas restricciones con la libertad de culto. El ensayo continúa presentando las respuestas dadas a la situación de restricción de movilidad y reunión, tanto por parte de la Iglesia católica, como por parte de los fieles y autoridades dentro de distintos países. Para terminar, se presentan las reflexiones conclusivas de ambos autores.

\section{La vivencia de la religión en el tiempo: Un recuento general}

La religión católica es una de las confesiones de fe humanas más antiguas, y tiene una importancia tal que pudiéramos afirmar que es repaso obligatorio para cualquier análisis sociológico, histórico y jurídico de la sociedad occidental. Esta incluso ha moldeado el pensamiento jurídico en grandes etapas de la historia. En Latinoamérica y Europa esta fue el fundamento de gran parte de la conciencia de la población, logrando crear una cultura que por muchos años guío el diseño jurídico de diversos países.

La Iglesia católica durante muchos siglos se constituyó como el poder más grande dentro de Europa. Así pues, durante los siglos V y XV la religión definió parte fundamental de las actividades de 
Vera-García., V., \& Duarte-Tello., F.

la población, gran parte de la población se componía de candidatos seleccionados al bautismo y estos eran preparados para dar un paso a ser evangelizados o convertidos a la fe. Durante la primera etapa de la Edad Media el bautismo de los niños se generalizó y por tanto las conversiones se realizaban en masa hacia los pueblos. Esto tuvo como consecuencia que la voluntad de los jefes de cada esfera social fuera la norma máxima y la inclusión de pastores laicos no eran los suficientes para corregir diversos errores que ocasionaban estos últimos. El analfabetismo era una característica principal de la población cristiana y de estos saldrían muchos de los sacerdotes que componían gran parte de las figuras de autoridad en la sociedad (De Pablo Maroto, 1997, pp. 121-185).

Es importante señalar que la población, al desarrollarse con una influencia religiosa, trae como consecuencia un diseño social basado en ella. La Edad Media pese a todas sus aportaciones, constituyó uno de los episodios más atroces de la humanidad, sin embargo, autores cómo De Pablo señalan que, para otros, representó una forma de mirar la evolución humana. Esto debido a que precisamente el cambio de paradigmas establecidos antiguamente forjó un nuevo dogma que se incrustaba en la base primordial del Estado (De Pablo Maroto, 1997, 121-185). La religión católica inclusive forjó una de las etapas de la soberanía del Estado, en donde la figura de esta, representaba la máxima potestad, la cual posteriormente sería sobrepasada por la figura del rey que haría una contundente auto asignación al definirse a sí mismo como El Estado debido a su triunfo sobre la gran autoridad de la Iglesia y de los señores feudales que durante esta etapa constituían las voluntades máximas, minimizando la figura del rey y pasando significativamente por encima de ella (Tena Ramírez, 1978, pp. 39-43).

Posteriormente dentro del siglo XIX la colonización de los países europeos en América generaría pequeñas sociedades que mezclarían parte de sus tradiciones culturales con la imposición del catolicismo. Esto produciría una nueva etapa de la humanidad en donde la imposición tanto del castellano, costumbres y religión, formarían un nuevo modelo social que no era completamente puro a comparación de los países católicos de Europa, pero que logró dar una nueva visión a la práctica de la religión. Examinar la historia principalmente de los países latinoamericanos es ver un reflejo del inicio del proceso evolutivo de la experiencia europea. Las colonias poco a poco lograrían realizar sus revoluciones y modificarían la potestad generada por sus colonos para lograr crear nuevos diseños de Estado (con bastantes fallas). Dichos Estados querían desapegarse de lo que sus antiguos conquistadores diseñaron, pero que al final solamente lograron ser un nuevo reflejo con diversas mutaciones de lo que ya había sucedido en el viejo continente. El arte, la cultura, las prácticas sociales, costumbres, política, economía, todo en América se basaba en la experiencia del catolicismo como pilar fundamental. Por muchos años el constitucionalismo 
en América, estableció como religión única y oficial la católica. Incluso en la Constitución de 1824 de México se establecía en el artículo 3 a la religión católica, apostólica y romana como la religión de la nación mexicana. Además, el preámbulo de la constitución definía la creencia de que Dios era el “Supremo legislador” de la sociedad (Hernández Gaona 1993: 391).

Con el paso del tiempo, a pesar de que la religión católica se convirtió en la fe predominante de América Latina, las distintas creencias se han vuelto más permitidas. La sociedad multi-religiosa provocada por la inmigración y misiones realizadas por la propia iglesia, trajo consigo el problema de reconocer la libre religión tanto en el aspecto individual como en el colectivo. El arraigo a las tradiciones y dogmas generó polémica en la transición del Estado plenamente católico al laico, las leyes poco a poco se fueron adaptando hasta cambiar aquellas costumbres legislativas y argumentativas que se centraban en la ideología generada por el catolicismo. La prohibición de preferencias sexuales distintas a la heterosexualidad, el rol de la mujer, inclusive el rol del propio hombre, estaban influenciados de manera constante por las ideas religiosas y ortodoxas heredadas por generaciones, sin embargo, las nuevas realidades, problemáticas y la nueva forma de ver al Estado generaron una conciencia más tolerante hacia estos (Osuchowska, 2014, 64-86).

Gran parte de los Estados reconocieron el respeto de otras religiones y adecuaron su sistema al principio de laicidad, con la finalidad de no influir en la conciencia tanto individual como colectiva de la población y así permitir el libre desarrollo de la personalidad de cada una de las personas. En la actualidad el papel de la religiosidad representa parte de la evolución dentro de la modernización, haciendo que la concepción tradicional haya cambiado en gran parte de los países que se concebían como católicos. Esto permitió a la libertad de culto darles a los países una visión más integral y menos discriminatoria, creando así, una mayor convivencia y respeto hacia los demás.

\section{2.- MÉTODO}

\section{Diseño}

Para cumplir el objetivo del presente trabajo se empleó un diseño metodológico consistente en la recabación de documentos para su lectura y estudio. Este fue el único diseño metodológico seguido que corresponde con una técnica de investigación hermenéutica. Por tanto, las herramientas que los presentes empleamos fueron diversos documentos entre los cuales se encuentran libros de doctrina jurídica, artículos de divulgación científica y notas periodísticas que tuvieran relación con los temas propios de la 
Vera-García., V., \& Duarte-Tello., F.

investigación que son las medidas de restricción de movilidad y reunión, el derecho de libertad de culto y las respuestas de autoridades católicas y feligreses ante dichas medidas. De igual manera se consultaron sentencias emitidas por tribunales y decretos ejecutivos y legislativos de los países estudiados que tuvieran relación con los temas citados.

Como ya se adelantaba en la introducción, los criterios de inclusión o exclusión fueron la búsqueda de países con una tradición religiosa católica. De igual forma nos enfocamos en países europeos y latinoamericanos debido a sus similitudes en cuanto a sus sistemas jurídicos, basados en el derecho continental.

\section{Instrumentos}

Para la presente investigación se utilizó un método de investigación hermenéutico únicamente. No se realizó un trabajo que implicara la realización de un método de investigación cuantitativo. Pese a que en el documento se mencionan algunas estadísticas, estas fueron incluidas con la intención de mostrar un panorama sistémico de la situación creada por la pandemia en los países estudiados. La razón de esto es debido a que la intención del trabajo es puramente descriptiva.

Por otro lado, no se utilizó instrumento alguno más que la toma de notas para dividir las consultas realizadas por área temática y por países, agrupando sus similitudes y señalando sus diferencias. La confiabilidad de dicho instrumento es meramente aquel que puede atribuirse a la falibilidad humana,

pues si bien se tuvo especial cuidado de no dejar de lado algún dato relevante o de desechar aquellos que pudieran ser innecesarios, la realidad es que los errores pueden estar ahí presentes. Además, en general el análisis de documentos puede caer en la subjetividad, pero se buscó de igual manera no dejarse llevar por prejuicios o ideales preconcebidos de los autores.

\section{Procedimientos}

Las fases de la investigación fueron sencillas. Primero se inició con la observación de la situación a través de noticias y posteriormente se procedió a la reunión de información por medio de artículos y libros; así mismo se consultaron diversos decretos ejecutivos y legales de los distintos países que han implementado medidas restrictivas de movilidad y reunión para hacer frente a la pandemia. Posteriormente se observó nuevamente a través de noticias y algún que otro documento oficial de las autoridades católicas la respuesta tanto de estas como de los feligreses respecto de las medidas de restricción. 


\section{3.- DESARROLLO DEL TRABAJO}

\section{La vivencia de la Fe católica en el siglo XXI antes del COVID-19.}

La religión católica si bien ya no es obligatoria dentro de los Estados, sigue teniendo una dominación considerable dentro de la población (El Annuarium Statisticum Ecclesiae, es un documento estadístico publicado por la Iglesia católica y en su versión del año 2017 estableció que en una población mundial de 7,408 millones, los católicos bautizados son 1,313 millones, lo que equivale al 17.7\% de la población y distribuidos por continente estos son los porcentajes: $48.5 \%$ en América, $21.8 \%$ en Europa, $17.8 \%$ en África, $11.1 \% \%$ en Asia y $0.8 \%$ en Oceanía.), principalmente en América siendo esta la mitad del total. Antes de la pandemia las rutinas en el ejercicio de la religión católica se organizaban conforme a un calendario semanal, distribuyendo las misas y otro tipo de actividades de los días, a donde acudían miles de creyentes. De igual forma, las tendencias de las prácticas religiosas en nuestro siglo variaron notablemente, los procesos religiosos al igual que costumbres sociales no se mantienen de la misma forma, por lo que los antiguos sacrificios realizados, en nuestros tiempos representan más una alegoría que un requisito real para practicar el catolicismo. El ejercicio de estas prácticas tuvieron que adecuarse al fenómeno de la globalización que logró no solamente darle una nueva visión a la institución de la religión, sino que también permitió que esta no se ahogara en un marco de tradiciones, ritos y costumbres antiguas que no se ajustaran a la realidad actual, así pues, el catolicismo obligatorio y recalcitrante que se metía en el desarrollo de la personalidad del individuo mutó, de tal forma que se volvió un componente en donde las personas por medio de su voluntad practican la religión.

En el siglo XXI ciertas ceremonias siguen presentando de forma inconsciente una influencia del catolicismo que durante muchos años perduró. Los bautizos, las bodas, misas en honor a los difuntos, reuniones de carácter más social, retiros espirituales, son solo algunas pocas de las muchas de las actividades que los fieles realizan en su propia libertad y que llevan a cabo cotidianamente haciéndola parte elemental de su vida. Sin embargo, el catolicismo en el siglo XXI presenta un declive dentro de su ejercicio, la resistencia a la actualización de los preceptos católicos y el seguimiento de la escuela ortodoxa ha traído consigo la pérdida del interés que antaño atraía a miles de seguidores. En la Europa occidental el catolicismo se muestra desvitalizado y reemplazado por varios grupos carismáticos de carácter protestante. Por tanto, la iglesia al momento de la elección del titular de la "Santa Sede" prefirió con Francisco rejuvenecer los ideales del catolicismo a fin de ajustarse a las necesidades actuales y realidades de la sociedad (Moran, 2016, pp. 1-40). 
Vera-García., V., \& Duarte-Tello., F.

Esta necesidad de revitalizarse constituyó uno de los cambios más significativos por parte de la Iglesia católica, y cambió en gran parte el desarrollo de actividades de los creyentes. Así la religión Católica se convertiría en el siglo XXI tanto para los antiguos y nuevos fieles, en un escape a las diversas realidades que cada uno experimenta en su vida, es decir, la religión si la analizamos desde cierta perspectiva, sirve para fortalecer la estabilidad mental de las personas. Es así como este rejuvenecimiento que experimenta el catolicismo es de vital importancia pues deja atrás el relativismo moral de Benedicto XVI y da paso a una nueva cultura y prácticas impulsadas por el nuevo pontífice para atender a la concepción de la iglesia de los pobres, una especie de democracia que se centraría en el amor, simplicidad, intelectualidad, el perdón y dejar a un lado los señalamientos hacia grupos vulnerables que tenían un protagonismo nulo dentro del ejercicio de esta religión.

Así la iglesia, se presenta como una especie de recinto reformador que puede atender a miles de personas, y por tanto ellas, pueden desenvolverse adecuadamente como si se tratara de una especie de terapia psicológica ante las adversidades de la vida cotidiana, de nueva cuenta, recordemos que la humanidad vive sumida en un campo rutinario que cada vez se deshumaniza más, las intensas jornadas de trabajo cansan la mente de cada uno de los y las trabajadoras tomando el control completo de sus días, por lo que las actividades en materia de culto, constituyen una salida y nueva esperanza para ellos (Moran, 2016, pp. 1-40).

\section{El derecho a profesar la fe y el derecho a la salud pública.}

La actual contingencia sanitaria ha traído consigo diversas problemáticas que, en su momento no se planteaban en la consciencia ni de la población ni de los titulares de los diversos poderes del Estado. Estas han quitado la venda de los ojos a miles de juristas que alrededor del mundo establecían su modelo como uno complejo y que se aterrizaba a las necesidades sociales, lo que claramente era más un espejismo que realidad. El derecho de profesar la fe es uno de los derechos fundamentales que ha colisionado con el derecho a la salud pública, y que ha dejado diversas interrogantes sobre cómo debe de actuar la comunidad creyente ante esta situación.

Profesar la fe de forma libre, ha sido un proceso evolutivo que ha pasado por diferentes etapas. Si bien, las personas realizaban actos tendientes a expresar su religión, esta era condicionada, debido a que eran los propios gobernantes los que establecían que religión se tenía que seguir. La Paz de Augsburgo firmada el 25 de septiembre del año de 1555 durante la mitad del siglo XVI, trataría de 
propulsar la libre religión, este acuerdo realizado entre católicos y confesionalitas, tendría como finalidad el poder alcanzar un grado mayor de paz religiosa, al reconocer el pluralismo religioso en aquel contexto histórico (Vera Urbano, 1983, 509-514).

Si bien, este pluralismo se encontraba un tanto delimitado por la voluntad del señor feudal hacía sus súbditos, la intención era crear un ambiente de calma ante las constantes luchas por motivos de religión. Así pues, por medio de este tratado, los Estados se obligaban no sólo a respetar la religión de las personas a su cargo, sino que, además reconocían la existencia de otra cosmovisión religiosa diferente a la suya. Con lo anterior igual evitaban influir en ella, y crear cierto grado de diplomacia ante algún conflicto. En este sentido, el contexto es de vital importancia para delimitar una posible solución, en el presente supuesto, hablamos de una época, donde evidentemente la noción de libertad era más un ideal, sin embargo, este antecedente fue de vital importancia, puesto que como recordamos, la religión era uno de los mayores motivos de desplazamiento al igual que el comercio, por lo que la concurrencia de devotos en un mismo lugar era muy común, pues el ejercicio de profesión de la fe es en mayoría, un acto de índole colectiva, que si bien parte de una espiritualidad interna, se expresa en gran medida en conjunto con otras personas afines a ella. En el contexto de esta colisión de derechos, podemos tomar de referencia ciertos artículos y casos en los que esto se ha visto contrapuesto y como la argumentación en la interpretación de estos derechos recae mucho en el contexto del que se trate. En primer lugar, tendríamos la problemática que nace de analizar ciertas posturas en relación con la religión y la salud. En este sentido, algunas corrientes religiosas en Latinoamérica dan significado a los malestares percibidos hacia la persona desde esta perspectiva de la noción del espíritu, persona, estado de la psique y otros más. Por lo que la cura, según esta visión viene del espíritu, la psicología y el cuerpo. Por tanto, el someter enfermos a profesionales de la salud debe de ir en conjunto con un grupo de médicos y psiquiatras además de reintegrarlo a la comunidad religiosa (Giménez Béliveau et al. 2018, pp. 153-159).

Dentro del Convenio Europeo de Derechos Humanos (Convenio EDH) en el artículo 9 se establece la libertad de pensamiento, conciencia y religión y este establece los límites de su alcance, así como las restricciones. El artículo establece la prohibición de restringir este derecho por motivos que no sean óptimos para preservar principios fundamentales en la democracia del respectivo país, por lo que sí es permisible establecer restricciones que tengan como objetivo la protección de los principios de estas sociedades, y uno de estos principios es la salud pública. Por tanto, es válido según el Convenio establecer restricciones en este sentido, pues la legitimidad radica en entender que son necesarias las suspensiones de ciertos eventos de índole religiosa con motivo de preservar la salud pública. Considerando lo anterior, 
Vera-García., V., \& Duarte-Tello., F.

es factible que los Estados establezcan limitaciones, pero también lo es, fundamentar la decisión en un contexto adecuado, por tanto, la situación de emergencia actual y que ha cobrado miles de víctimas puede ser tomada como legítima ante el riesgo que conlleva permitir la realización de estos eventos en la salud de las personas. Como sabemos el Tribunal Europeo de Derechos Humanos en conjunto con el Convenio EDH ha desarrollado el concepto de margen de apreciación amplio en cuanto a las limitaciones de ciertos derechos y los mantiene sujetos a tres fines distintos. El primero de ellos es que se encuentre previsto en una ley, el segundo que siga una finalidad legítima y el tercero que sea necesario en una sociedad democrática (Legg, 2012, 186).

Teniendo estos tres supuestos, lo que queda es desarrollar la argumentación con base al contexto actual de la emergencia sanitaria, por tanto, el primer punto al hablar de la previsión en una ley sería válido puesto que casi todos los Estados en Europa dentro de sus finalidades primordiales es la protección al derecho de salud y más si se trata de una pandemia que afecta no solamente a la legalidad de una norma, sino que va más allá de ella al poner en peligro de contagio a miles de personas. En segundo lugar, la finalidad legítima, se ha ido estableciendo por el Tribunal el justificar dichas limitaciones en el sentido que de reconocer algún acto derivado de una comunidad o convicción religiosa que ponga en peligro la seguridad pública está plenamente justificada. Al final, entonces tendríamos la necesidad de la restricción o limitación en una sociedad democrática la cual se argumenta a favor de la libre religión al preservar el pluralismo, sin embargo, al tratarse de un riesgo potencial el practicar estas actividades pone seriamente en una situación vulnerable a las personas que convivan cerca de estas comunidades.

Por su parte, la Convención Americana sobre Derechos Humanos señala dentro de su artículo 12 la libertad de conciencia y de religión, y en el mismo sentido que el Convenio EDH señala la prohibición de limitar este derecho excepto cuando se trate de una cuestión necesaria para proteger la seguridad, el orden y la salud. Por tanto, la legitimidad de dichas restricciones es válida al limitar el ejercicio de este derecho a fin de preservar la salud pública. En este sentido, el establecer el derecho a la salud como un límite a la libertad de religión sería completamente válido debido a las posiciones anteriormente descritas. Cabe señalar que estas restricciones van de la mano con las consideraciones de los Estados a fin de preservar la salud como lo puede ser el suspender ciertos eventos sociales, públicos y tomar la vía de dispositivos online como forma de llevarlas a cabo por lo que una restricción al acceso a estos medios no estaría justificada, debido a que el peligro potencial de contagios es por medio de vías presenciales y no de conexión remota. 
Queda entonces la discusión más bien, de si los Estados deben de aportar medidas que contribuyan al ejercicio no presencial de estas comunidades y personas, debido a que como se dijo antes, este tipo de actividades conforman parte del libre desarrollo de la personalidad y determinación de cada una de las personas, sin contar el hecho de lo que esta fe representa para muchas otras, al ser un escape y medio terapéutico para sobrepasar las desgracias y conflictos del diario o bien, disfrutar de la esperanza que se deposita en ellos.

Las medidas de restricción de movilidad y el derecho de profesar la fe: Breve panorama comparado.

Ya se han presentado algunas consideraciones sobre lo que implica el derecho a profesar la fe y su relación con el derecho a la salud pública. Así pues, se concluyó que es completamente justificable limitar el derecho de culto en ciertos momentos de necesidad como el presentado por la pandemia. Ahora hablaremos sobre el impacto que han tenido las medidas de restricción de movilidad en el derecho que tienen las personas a profesar una religión. Como ya se anticipó en la introducción, profesar una religión no significa únicamente ser libre de tener una creencia determinada, sino que implica el derecho a practicar los ritos de culto y mostrar dichas creencias frente a terceros, como lo ha establecido el Tribunal Constitucional español (Trib. Const., sentencia núm. 177/199, 11 noviembre 2020: Fj 9).

Ante el escenario de pandemia que se ha venido viviendo a nivel mundial, por lo menos desde el mes de febrero de 2020, casi todos los países del mundo han establecido medidas de restricción de movilidad y de reuniones grupales. La libertad de profesar una religión no sólo se vive en la intimidad, sino que es un acontecimiento social y público. Por tanto, las mencionadas restricciones han afectado también el citado derecho. De los decretos o acuerdos que se han emitido, algunos de ellos hablan expresamente de las prácticas religiosas y otros sólo lo dejan implícito al mencionar la prohibición de reuniones de manera general. Cabe señalar que, aunque el presente trabajo se enfoca en la vivencia de la fe católica, las restricciones corresponden a todas las denominaciones religiosas en general. A continuación, se señalan de forma breve las situaciones que algunos países europeos y latinoamericanos han enfrentado con el inicio de la pandemia, como cada uno respondió a la misma y cómo estas respuestas afectan el derecho de libertad de profesar la religión.

\section{Alemania}

En el país de Europa Central el primer caso de coronavirus se registró el 27 de enero del año 2020 en el estado federado de Baviera, en donde se ha registrado la mayor concentración de casos del virus. En 
Vera-García., V., \& Duarte-Tello., F.

Alemania al 13 de mayo del año en mención se habían registrado 7,634 muertes, de las cuales 2,209 fueron en Baviera. Todavía a marzo de 2021 los casos de coronavirus siguen siendo constantes e incluso van en aumento de unas semanas a otras, siendo, por ejemplo, que al 5 de marzo se habían registrado en el país 10,580 nuevos casos a comparación de los 9,997 de la semana pasada (The Local, 2021). Ahora bien, Alemania se encuentra en una situación intermedia entre la separación de la Iglesia y el Estado y lo que se denomina un Estado Eclesiástico. Esto se puede apreciar en el hecho de que en el país las denominaciones religiosas con mayor presencia e incluso aquellas que no tienen tanta, pero cuentan con una importancia tienen el estatus de corporaciones de derecho público (Berkman, 2020, p. 180).

En Alemania se cuenta con la Ley de Prevención y Control de las Enfermedades Infecciosas en los Seres Humanos (Infektionsschutzgesetz - IfSG). Esta ley en su artículo 28 establece que la autoridad competente puede restringir o prohibir eventos públicos u otras reuniones de personas bajo ciertas condiciones. Ahora bien, esta ley federal debe ser implementada por cada Land alemán y así el 16 de marzo de 2020 el Gobierno Federal y los primeros ministros de los Länder promulgaron un acuerdo denominado Directrices para Frenar la Propagación del Coronavirus (The Federal Goverment, 2021). En la directriz número III de este acuerdo se nos dice específicamente, que además de otras reuniones de carácter recreativo o educativo, las reuniones en iglesias, mezquitas o sinagogas, así como las reuniones de otras comunidades religiosas, deben ser prohibidas.

Las restricciones para poder acudir a los centros de culto trajeron consigo diversas demandas y acciones judiciales. Sin embargo, de todos los casos que fueron presentados a la Corte Constitucional Federal alemana, sólo uno de dichos casos prosperó. Este fue el de una asociación de mezquitas islámicas de Baja Sajonia, que se decidió en la sentencia 1 BvQ 44/20. En dicho asunto un feligrés musulmán solicitaba el poder acudir a su mezquita local los viernes durante el mes del Ramadán para poder realizar sus oraciones. A criterio del tribunal, el reglamento que impedía el acudir a los templos era inválida puesto que las autoridades deben de dar la posibilidad de revisar el caso concreto y determinar si en efecto se pueden llevar a cabo ciertas actividades con las medidas pertinentes. Por lo tanto, no es válido que la prohibición sea absoluta, como en el caso del reglamento reclamado, sino que estos documentos de restricciones deben tener la posibilidad de que en circunstancias particulares se pueda acudir a los templos (Tribunal Constitucional Federal, 1 BvQ 44/20, 29 abril 2020: párr. 16).

Otros asuntos presentados en tribunales locales no llegaron a un estudio del fondo, pues se relacionaban con cuestiones de medidas provisionales. Diversos cuestionamientos se han presentado 
sobre las restricciones, como el hecho de si valía o no la pena pronunciarse sobre la validez o no de las medidas si las organizaciones religiosas ya habían cancelado los servicios de culto. Al final, en cada una de las decisiones de los tribunales el consenso parece estar en salvaguardar el derecho a la salud limitando en la medida de lo posible las manifestaciones públicas religiosas (Berkman, 2020, pp. 185 y 186).

\section{España}

En España el primer caso registrado de COVID-19 se dio a conocer el 31 de enero de 2020 en la isla de La Gomera, nueve días después se dio a conocer otro caso en Palma y fue el 24 de febrero cuando se detectaron los primeros casos en la península en la Comunidad de Madrid, Cataluña y la Comunidad Valenciana (Arroyo, 2020a). Con el paso de los días los contagios sólo fueron aumentando hasta superar los 4200 casos positivos de entre los cuales 120 personas fallecieron de acuerdo con el Ministerio de Sanidad (Arroyo, 2020b); fue entonces que el gobierno decidió tomar medidas. El gobierno español promulgó el Real Decreto 463/2020, de 14 de marzo, "por el que se declara el estado de alarma para la gestión de la situación de crisis sanitaria ocasionada por el COVID-19”. Con este estado de alarma se decretaba por quince días la restricción de casi todas las libertades de movimiento y producción económica, entre las restricciones se encontraban también prohibidas las reuniones públicas (Fernández Riquelme, 2020, p. 15).

A la anterior declaración le siguieron otras que modificaban o prorrogaban la misma, a saber, y como lista más bien ejemplificativa antes que extensiva podemos mencionar: el Real Decreto 465/2020, de 17 de marzo, por el que se modifica el Real Decreto 463/2020; el Real Decreto 487/2020, de 10 de abril, por el que se prorroga el estado de alarma declarado por el Real Decreto 463/2020; el Real Decreto 514/2020, de 8 de mayo, por el que se prorroga el estado de alarma declarado por el Real Decreto 463/2020; el Real Decreto 555/2020, de 5 de junio, por el que se prorroga el estado de alarma declarado por el Real Decreto 463/2020; y el Real Decreto-ley 21/2020, de 9 de junio, de medidas urgentes de prevención, contención y coordinación para hacer frente a la crisis sanitaria ocasionada por el COVID19.

En lo que se refiere a cuestiones de culto el Real Decreto contempló las mismas en su artículo 11. Este artículo hablaba no sólo de las ceremonias religiosas, sino también las civiles y a diferencia de lo que se pueda pensar el mismo no prohibía dichas celebraciones, sólo las condiciona a las medidas de sanidad decretadas y que los asistentes respeten la sana distancia de al menos un metro. Así mismo, en el anexo de lugar que deberán permanecer cerrados no se citan templos religiosos, por los cuales estos 
Vera-García., V., \& Duarte-Tello., F.

en teoría podrían seguir siendo visitados, sin embargo, se debe entender que, de acuerdo con las otras estipulaciones del Real Decreto, las concurrencias a dichos lugares deberían ser menores. Cabe destacar que a pesar de que con posterioridad el gobierno español continuó emitiendo modificaciones a sus decretos para ajustarse a las situaciones ocasionadas por la pandemia hasta el momento la resolución inicial respecto a las ceremonias civiles, de culto y religiosas no ha cambiado, se deben seguir adoptando las medidas pertinentes al momento de realizar dichas ceremonias.

Otros documentos destacados en relación con las restricciones de movimiento y la libertad religiosa son la Orden SND/386/2020, de 3 de mayo, por la que se flexibilizan determinadas restricciones sociales y se determinan las condiciones de desarrollo de la actividad de comercio minorista y de prestación de servicios, así como de las actividades de hostelería y restauración en los territorios menos afectados por la crisis sanitaria ocasionada por el COVID-19, que en su artículo 5 autoriza nuevamente los velatorios y entierros con límite de personas que participen en dichas actividades. Por su parte en el artículo 6 se permite la asistencia a lugares de culto siempre y cuando no se supere un tercio del aforo del recinto y se sigan las medidas de higiene. A esta orden sigue la Orden SND/399/2020, de 9 de mayo, para la flexibilización de determinadas restricciones de ámbito nacional, establecidas tras la declaración del estado de alarma en aplicación de la fase 1 del Plan para la transición hacia una nueva normalidad, que en su artículo 9 establece reglas para cuando el aforo de un recinto de culto no estuviere claramente determinado. Por último, tenemos la Orden SND/414/2020, de 16 de mayo, para la flexibilización de determinadas restricciones de ámbito nacional establecidas tras la declaración del estado de alarma en aplicación de la fase 2 del Plan para la transición hacia una nueva normalidad, que en su artículo 9 amplía la capacidad de asistencia al 50 por ciento del aforo del recinto de culto.

\section{Italia}

Italia fue el primer país europeo en confirmar un caso de COVID-19 en la ciudad de Codogno, Lombardía el día 21 de febrero de 2020. Con este primer caso confirmado se da por iniciada oficialmente la pandemia en Europa y así Italia se convirtió en uno de los países más golpeados por el nuevo tipo de coronavirus. A un año del inicio de la pandemia las autoridades han reportado que se tienen registrados al menos unos 2,800 millones de contagios y más de 95,000 fallecimientos. A febrero de 2021 se estima que la tasa de contagio diaria es de 636 casos por cada 100,000 habitantes. En el país se empezaron a tomar medidas para hacer frente a la pandemia desde el cinco de marzo cerrando centros educativos, el 8 de marzo se 
decretó a toda la región de Lombardía y otras catorce provincias más como zonas rojas y finalmente el 9 de marzo Italia se convirtió en el primer país del mundo en confinar todo su territorio (Tori, 2021).

El documento que puso a todo el país europeo en cuarentena fue el Decreto del Presidente del Consejo de Ministros, de 9 marzo 2020, que estipulaba en su artículo 1.2 que estaban prohibidas en todo el territorio nacional cualquier reunión de personas en lugares públicos o lugares abiertos al público. Ahora bien, dicho decreto sólo hace extensiva la restricción a toda la nación, pues es una ampliación de las disposiciones del Decreto-ley núm. 6, de 23 febrero 2020 y del Decreto del Consejo de Ministros de 8 marzo 2020.

Es en este último decreto donde se establecen todas las medidas que restringen la movilidad y las reuniones. Los eventos de carácter religioso también están contemplados específicamente en el artículo 1.1.g), donde se decreta su suspensión, junto con otras actividades de la vida cotidiana de las personas. Por otro lado, el decreto citado señala también lo conducente en cuanto a la apertura de lugares de culto. En el artículo 1.1.i) se nos dice que dicha apertura estará condicionada a la adopción de medidas de seguridad como el evitar aglomeraciones de personas y respetar la sana distancia establecida de 1 metro. Finalmente, en dicho artículo se nos dice también que quedan suspendidas las ceremonias civiles y religiosas, incluidas las funerarias.

\section{Brasil}

En Latinoamérica Brasil es el país que más ha sido golpeado por la pandemia, esto debido a la falta de una respuesta eficaz del gobierno para hacer frente a la situación desde que se confirmaron los primeros casos, según diversas opiniones (Gilbert, 2021; Royo Gual, 2021). De hecho, el país sudamericano es a marzo de 2021 el segundo país con más muertes registradas a causa del COVID-19, con una suma de 270,656 defunciones, sólo después de Estados Unidos. Se estima que el 21 por ciento de todas las muertes ocurridas en el mundo por la pandemia se encuentran registradas en este país (Redacción BBC News Mundo, 2021).

En dicho país se decretó el 6 de febrero de 2020 la Ley 13,979, que establecía medidas preventivas para hacer frente a la emergencia de salud pública derivada de la pandemia que se empezaba a vivir. Dicha ley en su artículo 3 estableció cuales eran las posibles medidas que debían implementarse por parte de las autoridades en la esfera de sus competencias. Entre estas se encontraban el aislamiento, la cuarentena y la realización de exámenes médicos o cualquier otro procedimiento de naturaleza clínica 
Vera-García., V., \& Duarte-Tello., F.

para determinar o salvaguardar la salud de las personas. En la primera versión de esta ley no existía una disposición específica que hablara de las actividades religiosas, sin embargo, a la misma se le fueron adicionando nuevos artículos y disposiciones entre las cuales se hace referencia cuestiones religiosas.

La Ley 14,019 de 2 julio 2020 modificó la primera a la que se hace referencia y adicionó el artículo 3-A, que decreta la obligatoriedad de usar cubrebocas para circular en espacios públicos y privados con vías de acceso públicas, así como en el transporte público. Además, en la fracción III de dicho artículo se establece el uso obligatorio del cubrebocas entre otros lugares, los templos religiosos. Por otro lado, la Ley 14,023 de 8 julio 2020 añade medidas para asegurar la salud de los profesionales considerados esenciales en el control de enfermedades y mantenimiento del orden público. Entre ellos se lista en el $\S 1$, fracción XX a aquellos trabajadores de los servicios funerarios y autopsias, actividades que se encuentran relacionadas con el ámbito religioso.

En las leyes anteriormente citadas no se habla específicamente de un confinamiento o restricción de reuniones obligatorios, sólo se enuncian las medidas que se pueden tomar para evitar la propagación de la pandemia, por tanto, se entiende que, al menos formalmente las actividades religiosas sólo están condicionadas al seguimiento de las medidas sanitarias de prevención.

\section{Colombia}

Muchos países latinoamericanos han sido golpeados por la pandemia de forma similar, Colombia es un país que debido a esta situación ha tenido que enfrentar una crisis política, económica, social y de salud sin precedentes. El primer caso se confirmó en una rueda de prensa el 6 de marzo de 2020, siendo la primera paciente una mujer joven que provenía de Europa. Sin embargo, mientras se anunciaba esto ya se conocía de otros casos de coronavirus en las ciudades de Bogotá, Medellín, Cartagena y Huila. A marzo de 2021, en Colombia se tiene un registro de 2,314,154 personas contagiadas, una cifra muy similar a la de otros países latinoamericanos como México y Argentina. La cifra de personas fallecidas varía, pues en Colombia los decesos 61,498, han sido menos que los de México y un poco mayores que los de Argentina, por ejemplo (Semana, 2021).

Para hacer frente a la pandemia en Colombia, se expidió el Decreto 457/2020, de 22 marzo 2020, por el cual se imparten instrucciones en virtud de la emergencia sanitaria generada por la pandemia del Coronavirus COVID-19 y el mantenimiento del orden público, el cual regula las medidas de aislamiento del país durante la cuarentena decretada. En dicho decreto el artículo 1 estipula los horarios desde que 
comienza el confinamiento hasta la tentativa fecha y hora en que finalizaría el mismo. Por su parte, el documento también señala en su artículo 3 que, para garantizar el derecho a la vida, las autoridades gubernamentales deberán permitir la circulación de las personas para realizar determinadas actividades. Entre dichas actividades destacan las señaladas por el apartado 9, que menciona las actividades funerarias, entierros y servicios fúnebres, así como el apartado 29 del mismo artículo que señala las actividades humanitarias y de ayuda espiritual.

Como se señaló, en Colombia no se restringió la asistencia a los templos o recintos de culto, sin embargo, sí se decretaron medidas de sanidad que en realidad son recomendaciones. Estas se estipularon en un documento denominado Recomendaciones para la prevención y contención del coronavirus (Covid-19), en el sector religioso, emitido por la Mesa Nacional de Asuntos Religiosos del Ministerio del Interior. En el citado documento se detallan las medidas que se deben de llevar a cabo durante las ceremonias religiosas, como evitar el tocamiento de manos entre personas, el uso del gel antibacterial, la desinfección de los instrumentos para los ritos o la evacuación rápida del recinto una vez finalizada la ceremonia. Cabe señalar que este documento, aunque es de carácter general tiene una inclinación implícita hacia las denominaciones cristianas.

\section{México}

En México, el primer caso positivo de COVID-19 se registró el 27 de febrero, por su parte el primer fallecimiento se registró el 18 de marzo, tres semanas después (Animal Político, 2020). Para dar respuesta al creciente número de contagios y de fallecimientos se publicó primero en el Diario Oficial de la Federación el “Acuerdo por el que el Consejo de Salubridad General reconoce la epidemia de enfermedad por el virus SARS-CoV2 (COVID-19) en México, como una enfermedad grave de atención prioritaria, así como se establecen las actividades de preparación y respuesta ante dicha epidemia" y el mismo día, de conformidad con dicho acuerdo la Secretaría de Salud decretó la Jornada Nacional de Sana Distancia, que se extendería hasta el 30 de mayo. Además de lo anterior cabe señalar que la Secretaría de Gobernación mediante el comunicado núm. 034/2020, de 31 marzo 2020 exhortaba a los centros de culto a suspender sus actividades (Gobierno de México, 2021).

Tras el periodo establecido se dio inicio a lo que se denominó nueva normalidad, acompañada de un método de medición de riesgo en forma de semáforo epidemiológico, el cual maneja cuatro colores: rojo, naranja, amarillo y verde. Dicho semáforo empezó con todas las entidades del país en rojo, para posteriormente el 12 de junio señalar doce estados en color naranja. Dicho semáforo ha traído consigo 
Vera-García., V., \& Duarte-Tello., F.

críticas por parte de cierto sector poblacional y algunas autoridades de las entidades federativas. En un video publicado por el portal de noticias Animal Político se declaró que, de acuerdo con las estimaciones, en las próximas semanas a su publicación (20 de agosto) en México se rebasaría el número de muertes en 60 mil. Lo anterior tras sólo seis meses de pandemia (Animal Político, 2020).

La Jornada Nacional de Sana Distancia no tuvo la fuerza que se buscaba para hacer frente a la pandemia por lo que algunas autoridades de las entidades federativas decidieron promulgar sus propios decretos de restricción de movilidad para hacer frente a la pandemia, como por ejemplo el estado de Veracruz que publicó un decreto de fecha 7 de mayo de 2020, denominado "Decreto por el que se determinan medidas temporales de inmediata aplicación para reducir la aglomeración y movilidad inusual derivado de la emergencia sanitaria generada por el virus SARS-Cov2 (COVID-19) en el territorio del Estado de Veracruz". Otro ejemplo es el de Coahuila con el "decreto por el que se emiten las disposiciones relativas a la movilidad de las personas en el Estado de Coahuila de Zaragoza durante la contingencia COVID-19" del 22 de abril.

Ahora bien, dentro de los múltiples folletos e información dada por parte de la Secretaría de Salud y del gobierno no se mencionó alguna medida relativa a ceremonias religiosas o de culto. En este sentido las medidas se limitaron a informar que se suspendían las actividades no esenciales que involucraran la congregación o movilidad de personas y que se sustituirán por actividades que promuevan la sana distancia (Secretaría de Salud, 2020). En este caso se puede entender que los ritos religiosos, incluidos los católicos son actividades no esenciales, así lo entendieron las autoridades que decretaron el cierre de los templos (Corpus Flores, 2020, p. 41).

Las respuestas de los fieles: Entre acomodo y peticiones.

Una vez visto cómo distintos Estados han respondido ante la pandemia del COVID-19 y la repercusión que las medidas tomadas han tenido sobre la libertad de culto, pasaremos a hablar sobre cómo se han vivido las restricciones por parte de las autoridades eclesiásticas y los feligreses. Primero que nada, hablaremos de la renovada religiosidad y las nuevas formas en que se está viviendo esta y posteriormente se hablará de casos en particular. Estos casos en particular son muestras tanto de la aceptación de las medidas restrictivas como de la disconformidad y desobediencia a las mismas.

La religión es uno de los aspectos de la vida al que más recurren las personas cuando se enfrentan a experiencias dramáticas como el enfrentar peligros que amenazan la vida misma. La pandemia 170 Revista Política, Globalidad y Ciudadanía | Vol. 7, Núm. 14, junio - diciembre 2021 | ISSN 2395-8448 | http://revpoliticas.uanl.mx/ 
provocada por el COVID-19 resulta ser una de esas experiencias dramáticas, por lo tanto, no resulta extraño corroborar que desde empezada la pandemia gran parte de la población haya acudido al consuelo que ofrecen las religiones, como la católica. Desde los primeros meses de la pandemia se ha detectado un incremento en la religiosidad en diversos países en el mundo. En una escala global se ha detectado un incremento del $50 \%$ de búsquedas en Google relacionadas con rezos a comparación de los días anteriores a la llegada del COVID-19. En una escala menor, un cuarto de la población adulta en Estados Unidos ha afirmado que su fe se ha incrementado debido a la pandemia de acuerdo con una encuesta del Pew Research Center. La situación cambia de acuerdo con los países pues mientras que en Italia se ha encontrado un incremento en la oración, en Países Bajos la cantidad de esta parece no haberse visto afectada (Molteni et al., 2021, p. 705).

Por su parte, debido a la cancelación de las celebraciones eucarísticas o fiestas religiosas como las de la Pascua la vivencia personal de los fieles se modificó rotundamente. En este sentido la tecnología resultó ser un importante aliado pues fue a través de las transmisiones en facebook o en otras plataformas digitales, los fieles podían unirse a las oraciones del rosario o sintonizar la misa dominical desde sus casas. Por otro lado, grupos pastorales o diocesanos, sacerdotes y obispos crearon grupos de WhatsApp para vivir y compartir la fe (Rodríguez Olivera, 2020, 82).

Cabe destacarse que, además, los tiempos que se dedican al culto se flexibilizaron; en segundo lugar, la incertidumbre provocada por la pandemia y todas sus repercusiones hacen más necesaria la comunicación con el ser divino; en tercero podemos señalar que los medios digitales ayudan a acercar al feligrés a figuras de liderazgo y así mismo, aunque parezca paradójico traen consigo la menor necesidad de intermediarios (Corpus Flores, 2020, pp. 44). Además, a través de entrevistas que se han realizado con personas practicantes de la fe católica se observa que muchas de ellas se han adaptado e incluso han encontrado mayor fuerza y unión familiar debido a la renovada religiosidad que se ha vivido a nivel mundial. También se han hecho más comunes las actividades de ayuda a los más necesitados (Rodríguez Olivera, 2020, pp. 88 y ss.).

Ahora bien, la respuesta de las autoridades eclesiásticas fue en general acorde con las disposiciones que decretaron los gobiernos. De hecho, en Italia, el Papa Francisco anunció que las ceremonias relacionadas con la Pascua católica se realizarían en la Basílica de San Pablo como es acostumbrado, pero sin asistencia por parte de los fieles y que serían transmitidas a través de los medios digitales (San Martín, 2020). En el mismo país otros párrocos como Don Andrea Vena, sacerdote de la 
Vera-García., V., \& Duarte-Tello., F.

ciudad de Venecia han recurrido a prácticas creativas como subir a una camioneta y comenzar a bendecir a la población a través de un megáfono (Roberts y Stamouli, 2020).

En Colombia por ejemplo la Conferencia Episcopal emitió un comunicado manifestando su apoyo a las medidas interpuestas por el gobierno. Pidiendo así a la comunidad que mantuviera la calma y a aquellos feligreses que presentaran síntomas se les conmino a que no asistieran a misa. Sacerdotes de Colombia señalaron que las medias son consideradas por la Iglesia como sabias y prudentes, así mismo han reiterado la importancia que tienen para los sacerdotes la dignidad y el cuidado de las personas (Redacción Vida, 2020). En Paraguay sucedió algo similar, pues hasta el 8 de 2020 los fieles católicos podían continuar acudiendo a las celebraciones eucarísticas, para lo cual la Conferencia Episcopal Paraguaya emitió un protocolo que contenía medidas de seguridad e higiene durante las celebraciones religiosas. Sin embargo, cuando en el país aumentaron los contagios y las restricciones de movilidad por parte del gobierno fueron más severas, la misma Iglesia hizo un llamado a los feligreses con el slogan "quédate en casa", avocándose al uso de las redes sociales para continuar con su labor (Rodríguez Olivera, 2020, p. 83).

En México hubo también un ambiente de cooperación de las autoridades religiosas con las disposiciones gubernamentales. La Conferencia del Episcopado Mexicano, por ejemplo, publicó el Comunicado COVID-19 Emergencia Sanitaria, de 16 marzo 2020 (Conferencia del Episcopado Mexicano, 2021), en donde se ordenaba a los obispos del país suspender encuentros de grupos numerosos y las celebraciones de las misas. Por otro lado, pide que se facilite en la medida de lo posible la transmisión de las misas a través de plataformas digitales y medios de comunicación públicos y privados.

La labor de las autoridades eclesiásticas no sólo es de guía espiritual, sino que, debido a su fuerte influencia en las convicciones de sus feligreses, también tienen una labor de guías en lo que las personas deberían o no hacer. Las opiniones de los sacerdotes son muy importantes para muchos, por eso destaca en momentos más recientes de la pandemia la labor que se lleva a cabo en Filipinas para que la población acepte ser vacunada en contra del virus.

No es extraño observar que muchas personas en el mundo tienen un recelo en contra de las vacunas. Se puede destacar, por ejemplo, el caso de Filipinas en donde aún se recuerda la controversia de la vacuna contra el dengue de 2018. En aquel momento se argumentó que la citada vacuna condujo a la muerte de más de cien personas. Es por eso por lo que, en el caso de las vacunas que se están 
suministrando contra el COVID-19, la Iglesia católica ha decidido realizar una iniciativa de vacunación de sus miembros. Poniendo así el ejemplo y siguiendo ellos mismos el ejemplo del Papa Francisco que recibió la vacuna en enero de 2021, para incentivar la confianza de la población en las vacunas. Así pues, se considera que la colaboración entre los gobiernos y la Iglesia ayudará mucho no sólo en Filipinas, sino en otras partes del mundo a promover la necesidad de la vacunación, sobre todo en países con una influencia católica importante (Gopez, 2021, p. 1).

Ahora bien, respecto a las manifestaciones de disconformidad o desobediencia de las medidas podemos mencionar algunos ejemplos. En Italia, en la parroquia de Santa María Mater Ecclesiae de via Solangai, en el barrio de Torrino, al sur de Roma, el sacerdote ha seguido celebrando misa. Lo que podría ser un problema de esta situación es que, en muchas de las celebraciones, aunque las personas mantienen las sanas distancias, al momento de la eucaristía, esto es la parte de la misa donde los fieles reciben el “cuerpo de Cristo", el sacerdote no usa guantes o cubrebocas (Algañaraz, 2020). Si bien vemos que en algunos lugares la prohibición de las celebraciones religiosas no está del todo prohibida, este si deben de cumplir las medidas de seguridad decretadas. También ha habido situaciones interesantes en ciertos Estados que apelan a una fe colectiva para ser protegidos ante el coronavirus. Tal es el caso de Bolivia, cuya presidenta interina Jeanine Áñez solicitó la ayuda de Dios a través de un comunicado por la televisión y convocó al ayuno y oración por un día entero como forma de enfrentar la pandemia (El Economista, 2020).

En algunos países tanto europeos como latinoamericanos se empezó a dar un pequeño movimiento de parte de reducidos grupos religiosos que exigían a las autoridades católicas, no al gobierno, la reapertura de los templos y la posibilidad de celebrar la misa. Destaca el movimiento en Europa de grupos de jóvenes austriacos, españoles, franceses y alemanes que a través de videos publicados en internet solicitaron a los obispos que les “devuelvan la Misa” (LifeSite News, 2020). Incluso algunos grupos políticos en España apoyaban las solicitudes de reapertura de templos (Rubin, 2020; Redacción Hispanidad, 2020). En Argentina, tres obispos opinaron sobre las solicitudes y las desestimaron como poco razonables, recordando a los feligreses que lo más importante en el momento era la procuración y cuidado de la salud de la población, en especial de la de riesgo (Religión Confidencial, 2020).

Un suceso interesante se dio en abril y al parecer tuvo una especie de efecto dominó. Lo que aconteció fue que a través de redes sociales circuló un video donde se alegaba supuestamente la persecución policíaca por parte de la Guardia Civil en España, en contra de personas fuera de una iglesia. 
Vera-García., V., \& Duarte-Tello., F.

Aparentemente lo único que exigían las personas era poder acudir al templo y celebrar la misa. Este video fue utilizado por parte de grupos católicos concretos, tal vez en contra del gobierno, para señalar por una parte la intransigencia de las autoridades y por otra lo importante que es para ellos la celebración de la misa. Este video resultó al final ser sacado de contexto pues fue publicado el 14 octubre de 2019 cuando un grupo de personas quería entrar a la Basílica del Valle de los Caídos, donde estaban enterrados los restos del general Francisco Franco, algunos meses antes de que se diera en el mundo siquiera el primer caso de COVID-19 (Redacción Animal Político, 2020). No obstante, el video no tiene nada que ver con el acontecimiento de la pandemia, que parece que dio algunos frutos. Pese a que no viene a cuenta del presente ensayo resulta interesante y no está de más recordar lo importante que es la verificación de fake news en un contexto como el que nos encontramos para evitar situaciones alarmistas.

Cabe decir que las anteriores situaciones son muy aisladas y los movimientos de rebeldía o de protesta en contra de las medidas de restricción, al menos en materia de profesión de fe y ceremonias religiosas, no tuvieron mucha convocatoria. La realidad mayoritaria fue, al contrario. Gracias a la comunicación eficiente entre autoridades y feligreses y sus representantes se pudo llevar a cabo la tradicional celebración de la Pasión en Iztapalapa en México, por ejemplo. Otra práctica que se modificó ante la situación fue la de las celebraciones, ya que muchos sacerdotes católicos han decidido celebrar misas a través de plataformas digitales (Corpus Flores, 2020, pp. 41 y 43). Tal es el caso, por mencionar un ejemplo, del papa Francisco que realizó diversas ceremonias durante la Pascua en el mes de abril y que aún sigue transmitiendo por medios digitales la celebración de la misa (Domènech, 2020; Vatican News, 2020).

Por último, debido a la pandemia y las restricciones de movimiento y reunión que la misma trajo, se presentaron otros fenómenos sociales. Entre ellos se encuentra un nuevo concepto social denominado Hogar-Mundo. Este concepto ha tomado fuerza entre los nuevos puritanismos ligados a la religiosidad. En pocas palabras se refiere a una noción de que el ambiente hogareño, lo privado prima sobre lo público. Ya no se habla de llevar los valores familiares hacia afuera sino, una especie de hermetismo contra una “contaminación” del exterior (Gaytán Alcalá y Bernal, 2021). Por otro lado, la vivencia de la religiosidad entre las comunidades indígenas también representa un fenómeno digno de estudiarse aparte. Esto debido a las particularidades que para los pueblos indígenas representa su conexión con lo espiritual (Morayta Mendoza, 2021). 


\section{4.- CONCLUSIONES}

A lo largo del presente artículo se observó como diversos gobiernos tomaron en consideración las prácticas y actividades religiosas al momento de determinar las actividades que se podían continuar realizando y cuáles actividades no eran indispensables. Algunos gobiernos se enfocaron de forma consciente a regular las reuniones y actividades religiosas, mientras que otros sólo enunciaron las restricciones sin mayores detalles. Algunos países incluso tomaron una postura de decreto de medidas que, aunque en apariencia neutras, se enfocan bastante en regular las prácticas desde un punto de vista cristiano católico, como en el caso colombiano. Estas regulaciones fueron recibidas por algunos académicos con cuestionamientos y se preguntaron si no había otra forma de tomar medidas menos restrictivas para el desarrollo de actividades religiosas y la profesión del culto.

Por otro lado, las autoridades católicas recibieron con buen agrado las medidas y se adecuaron a ellas emitiendo sus propios comunicados y recomendaciones. Estas guías de actuación que coincidieron muchas veces con lo estipulado por los gobiernos fueron implementadas tanto por la máxima figura de autoridad católica, el Papa, hasta por las autoridades eclesiásticas de cada país. Por su parte la respuesta de los fieles también fue de aceptación y adaptación, puesto que, al no poder salir de sus domicilios, muchos recurrieron a otras alternativas para poder realizar sus prácticas religiosas.

En cuanto a la adaptación y búsqueda de alternativas cabe señalar la importancia que tuvieron y siguen teniendo las tecnologías actuales. Como son las redes sociales y las transmisiones en vivo (streamings), así como las conferencias o reuniones virtuales a través de plataformas como Zoom (Gutiérrez y de la Torre, 2020). Ya antes de la pandemia se utilizaban este tipo de herramientas. Incluso las transmisiones televisivas y radiofónicas eran ya una realidad que la misma Iglesia incorporó en su actividad durante el Concilio Vaticano II en el año de 1959 (Navarrete Canales, 2005, pp. 321-ss.). Sin embargo, internet ha demostrado tener un impacto más inmediato e interactivo, por lo cual no es de extrañarse que se hayan fortalecido las plataformas que ya vienen cobrando fuerza en la vida secular de las personas.

Ahora bien, también se observó en este trabajo que algunas figuras católicas decidieron no respetar las medidas y tomaron una actitud desafiante y de rebelión. Así mismo algunos feligreses decidieron protestar y exigieron que se les "regresara la misa". Sin embargo, se debe reconocer que este tipo de manifestaciones son más anecdóticas que comunes y han sido pocas las personas o grupos que se han opuesto a las medidas. Se debe recordar que incluso hubo situaciones en donde circularon supuestas 
Vera-García., V., \& Duarte-Tello., F.

evidencias de manifestaciones reprimidas, las cuales terminaron siendo noticias falsas, como en el caso español.

Por todo lo anterior consideramos que la problemática planteada con anterioridad fue resuelta y el objetivo del presente trabajo se cumplió. Esto es así debido a que se pudo apreciar el carácter adaptativo de la religión católica. Pues con el paso de los siglos y los años ha ido ajustándose a las necesidades de sus fieles sin comprometer o entender de forma distinta los principios sobre los cuales se ha fundado. Así mismo, lo estudiado nos demuestra que una parte significativa de la sociedad tiene un deseo importante de vivir y expresar su fe y que han sabido acomodar dicho deseo con la transformación de la sociedad empleando las herramientas que la modernidad trae consigo. Así pues, se nos muestra una idea de cómo podría evolucionar la vivencia de la religiosidad en los siguientes años. Ya que, tanto las personas como las autoridades han caído en la cuenta de que incluso a la distancia se pueden fortalecer los lazos de comunidad y en este caso de comunidad religiosa.

\section{REFERENCIAS}

Algañaraz, J. (2020, 27 abril). Polémica Coronavirus en Italia: dura pelea entre la Iglesia y el gobierno por las misas, que siguen prohibidas. Clarín, 27 abril. https://www.clarin.com/mundo/coronavirus-italia-dura-pelea-iglesia-gobierno-misas-siguenprohibidas_0_Vnb8UqeRI.html

Animal Político (2020, agosto 20). 60 mil muertes por COVID, el escenario catastrófico en México [Archivo de video]. https://youtu.be/Ve70haPMA5c

Arroyo, J. (2020a, 23 marzo). Coronavirus: infectados en España y la evolución del brote desde el origen. Redacción Médica. https://www.redaccionmedica.com/secciones/sanidadhoy/coronavirus-infectados-espana-y-evolucion-covid19-desde-origen-4148

Arroyo, J. (2020b, 13 marzo). Coronavirus: España declara el estado de alarma y prevé 10.000 infectados.

Redacción Medica. https://www.redaccionmedica.com/secciones/sanidad-hoy/coronavirusespana-declara-estado-alarma-por-covid-1823

Berkmann, B. J. (2020). The Covid-19 Crisis and Religious Freedom. The Interaction between State and Church Norms in Germany, Especially in Bavaria. Journal of Law, Religion and State, 8, 179200.

Conferencia del Episcopado Mexicano. (2021). Comunicado COVID-19 Emergencia Sanitaria. https://cem.org.mx/prensa/2823-Comunicado-COVID-19-Emergencia-Sanitaria.html 
Corpus Flores, A. (2020). Las iglesias, el COVID-19 y la nueva normalidad. Posibilidad Política, (23), 37-50.

Domènech, R. (2020, 12 abril). El Papa preside la misa del Domingo de Resurrección en una Basílica de San Pedro vacía. El Periódico. https://www.elperiodico.com/es/sociedad/20200412/papapreside-misa-domingo-resurreccion-basilica-san-pedro-vacia-7925386

El Economista (2020, 28 abril). Bolivia pide apoyo a Dios para vencer a Covid-19. El Economista. https://www.eleconomista.com.mx/internacionales/Bolivia-pide-apoyo-a-Dios-para-vencer-aCovid-19-20200428-0156.html

Fernández Riquelme, S. (2020). Primera Historia de la crisis del Coronavirus en España. La Razón histórica: revista hispanoamericana de historia de las ideas políticas y sociales, (extra 46), 1222.

Gaytán Alcalá, F. y Bernal, R. (2020). El castillo de la pureza. Concepto de Hogar Mundo y la irrupción de los Nuevos Puritanismos en el contexto de la pandemia de COVID 19. Comparative Cultural Studies - European and Latin American Perspectives, 6(13), 71-88.

Gilbert, A. (2021, 20 marzo). Uno de cada cuatro muertos en el mundo por covid-19 se entierra en Brasil. El Periódico. https://www.elperiodico.com/es/internacional/20210320/cuatro-muertos-mundocovid-19-11592852

Giménez Béliveau, V. (2018). Salud y religiones: prácticas y sentidos en diálogo y disputa. Salud Colectiva, 14(2), 153-159.

Gobierno de México. (2021). A las iglesias, asociaciones y agrupaciones religiosas de México. https://www.gob.mx/segob/prensa/a-las-iglesias-asociaciones-y-agrupaciones-religiosas-demexico?idiom $=$ es

Gopez, J. M. W. (2021). Building public trust in COVID-19 vaccines through the Catholic Church in the Philippines. Journal of Public Health, (s.n.), 1-2. https://doi.org/10.1093/pubmed/fdab036

Gutiérrez, C. y de la Torre, R. (2020). COVID-19: la pandemia como catalizador de la videogracia. Espiral Estudios sobre Estado y Sociedad, XXVII(78-79), 167-213.

Hernández Gaona, P. M. (1993). Visión Histórica de las Constituciones de México a través de las decisiones fundamentales. Universidad Nacional Autónoma de México.

Legg, A. (2012). The Margin of Appreciation in International Human Rights Law, Deference and Proportionality. Oxford University Press.

LifeSite News (2020, 27 abril). 'Give us back our Mass!': Young Catholics around the world plead with bishops. LifeSite. https://www.lifesitenews.com/blogs/give-us-back-our-mass-young-catholicsaround-the-world-plead-with-bishops 
Vera-García., V., \& Duarte-Tello., F.

Molteni, F. et al. (2021). Searching for comfort in religion: insecurity and religious behaviour during the COVID-19 pandemic in Italy. European Societies, 23(1), 704-720.

Moran, G. M. (2006). Los Retos Estructurales de la Iglesia Católica en la Sociedad del Siglo XXI. Reflexiones sobre los modelos eclesiales y la evolución de la tradición, el magisterio y el derecho de la iglesia católica. Rivista Telematica, (27), 1-40.

Morayta Mendoza, L. M. (2021). Religiosidad, dilemas y pandemia COVID-19 en un barrio de Ocotepec, Morelos. En L. E. Corona de la Peña y L. M. Morayta Mendoza (Coords.). Miradas históricas y antropológicas sobre la pandemia, COVID-19 (pp. 209-222). Sindicato Nacional de Profesores de Investigación Científica y del Docencia INAH. https://d1wqtxts1xzle7.cloudfront.net/65495967/2021_01_Miradas_historicas_y_antropologica s_COVID19.pdf?1611444754=\&response-contentdisposition=inline\%3B+filename\%3D01_Miradas_historicas_y_antropologicas.pdf\&Expires=1 624641466\&Signature $=$ dfvCgFBHAyLXULlqpyKqmG7UmWr3bbKYevIXonl75WtVQtYEkw fvIIb3j3Gz-

d3Q th387Su6 1KU5wIY1NuT28IkqNHSrhfFZclHd2XPJBIMJwAUuhmlelLq70dsUV4wZV yrqaQfFQoFsOC4Z-

MkXmwIlflBefVEEKFZ6j7U uV7SniSJYcVrVU8fev1C5 rohUr7OKUhew uMxO0IFOSXE cNx2Wf1IsZ86ReDpciyvZNnXGy4cq8saYqf619QpU3eF7Zno4ZXSe2uEQudy6eSNyzrrWOs5 Gr4qNgauKsxllRUXoA4cA6KgsNu9oX3etu09izQxo7mL3vtEKY5fCA_\&Key-PairId=APKAJLOHF5GGSLRBV4ZA

Navarrete Canales, A. (2005). La Iglesia y los medios de comunicación social. Cultura, 19, 313-344. http://www.revistacultura.com.pe/revistas/RCU_19_1_la-iglesia-y-los-medios-decomunicacion-social.pdf

Osuchowska, M. (2014). La Influencia de la Iglesia Católica en América Latina según las Normas Concordatarias. Estudios histórico-jurídicos, (17), 63-86.

De Pablo Maroto, D. (1997). Historia de la Espiritualidad Cristiana. Editorial de Espiritualidad.

Ramírez Calzadilla, J. (2002). La religiosidad latinoamericana y caribeña: un elemento de la identidad cultural. América Latina y El Caribe. Realidades Sociopolíticas e Identidad Cultural (pp. 215236). Ediciones Heinrich Böll.

Redacción Animal Político (2020, 16 marzo). No, en España la policía no impidió a ciudadanos ir a misa para rezar contra el coronavirus, Animal Político. https://www.animalpolitico.com/elsabueso/espana-policia-misa-coronavirus/ 
Vera-García., V., \& Duarte-Tello., F.

Redacción BBC News Mundo (2021, 12 marzo). Coronavirus: "Brasil se está convirtiendo en una amenaza para la salud pública mundial". BBC News Mundo. https://www.bbc.com/mundo/noticias-america-latina-56369474

Redacción Hispanidad (2020, 28 abril). La Junta de Andalucía, del PP, no del PSOE, pretende prohibir la comunión en las misas. Hispanidad. https://www.hispanidad.com/confidencial/juntaandalucia-pp-olvida-a-dios-dios-pretende-prohibir-comunion-misas_12018072_102.htm

Redacción Vida (2020, 10 marzo). La Iglesia católica toma medidas preventivas contra el Covid 19. El Tiempo. https://www.eltiempo.com/vida/religion/la-iglesia-cato-lica-toma-medidas-preventivascontra-el-covid-19-470972

Roberts, H. y Stamouli, N. (2020, 17 marzo). In Italy and beyond, churches grapple with coronavirus. Politico. https://www.politico.eu/article/coronavirus-church-online-live-stream-congregation/

Rodríguez Olivera, E. M. (2020). Vivencia de feligreses católicos en tiempos de COVID-19. Divulgación Académica, 1(1), 80-95.

Royo Gual, J. (2021, 5 marzo). Jair Bolsonaro a los brasileños, en pleno récord de contagios y muertes por Covid: "Dejad de lloriquear". El Mundo. https://www.elmundo.es/internacional/2021/03/05/604240ae21efa0c9618b45cc.html

Rubin, S. (2020, 26 abril). La pandemia y la fe Coronavirus en Argentina: 'Devuélvannos la misa', el reclamo que impulsan grupos de fieles católicos conservadores. Clarín. https://www.clarin.com/sociedad/coronavirus-argentina-devuelvannos-misa-reclamo-impulsangrupos-fieles-catolicos-conservadores_0_CYKrhXw7F.html

Semana (2021, 7 marzo). Coronavirus: la historia de los primeros casos confirmados en Colombia. Semana. https://www.semana.com/nacion/articulo/coronavirus-la-historia-de-los-primeroscasos-confirmados-en-colombia/202137/

San Martín, I. (2020, 14 marzo). Pope to celebrate Holy Week without the presence of the faithful. Crux. https://cruxnow.com/vatican/2020/03/pope-to-celebrate-holy-week-without-the-presence-ofthe-faithful/

Tena Ramírez, F. (1978). Derecho Constitucional Mexicano. Editorial Porrúa.

The Local (2021, 5 marzo). LATEST: What is the current coronavirus situation around Germany? The Local. https://www.thelocal.de/20210305/latest-what-is-the-current-coronavirus-situationaround-germany/

The Federal Goverment. (2021). Guidelines to slow the spread of the coronavirus. https://www.bundesregierung.de/breg-en/news/guidelines-to-slow-the-spread-of-thecoronavirus- 1731708 
Vera-García., V., \& Duarte-Tello., F.

Tori, M. (2021, 21 febrero): Italia, el foco de la pandemia en Europa, un año después del primer caso. Público. https://www.publico.es/internacional/coronavirus-italia-italia-foco-pandemia-europaano-despues-primer-caso.html

Vatican News (2020, 14 marzo). Sigue la Misa en Santa Marta en directo por otra semana. Vatican News. https://www.vaticannews.va/es/papa/news/2020-03/sigue-misa-santa-marta-directo-otrasemana.html

Vera Urbano, F. (1983). El punto de partida político de la libertad religiosa europea: Augsburgo y Westfalia. Revista Española de Derecho Canónico, 39(114), 509-514. 